\title{
Bilateral Basal Ganglia Calcification Secondary to FAHRs Syndrome: A Rare Entity
}

Anmol Nagaraj, Rajesh Parameshwaran Nair*, Sibhi Ganapathy and Lakshman IK

Department of Neurosurgery, Kasturba Medical College, Manipal University, Manipal, India

\begin{abstract}
Background and importance: Fahr's syndrome is also known as idiopathic calcification of the basal ganglia. It is described as a rare, degenerative, neuropsychiatric disorder characterized by seizures, extrapyramidal, and neuropsychiatric symptoms as a result of symmetric and bilateral calcifications within the basal ganglia. Involvement of the nucleus pallidus, the putamen, the dentate nucleus of the cerebellum, and the hemispheric white matter at the base of the skull, are common radiological hallmarks of this syndrome. The calcification probably occurs due to lipid deposition and demyelinization.

Clinical presentation: We present the case of a post thyroidectomy patient with hypoparathyroidism (HPT) with incidentally detected basal ganglia calcification (BGC). Retrospectively the patient was found to have hypocalcemia, secondary to a total thyroidectomy performed on her, 2 years ago. The second case was that of a 35 year old patient who presented with sudden onset of "worst headache of his life" since the previous night associated with multiple episodes of vomiting. Here we discuss our clinical dilemma and treatment strategy.

Conclusion: In presence of BGC, HPT should be investigated, especially in patients who have undergone thyroidectomy, since in the early stage, the recovery could be expedited with a precise diagnosis and prompt treatment. This case report illustrated the benefits of calcium supplementation and calcitriol, even with the patient being in advanced stage of disease.
\end{abstract}

Keywords: Fahr's syndrome; Basal ganglia calcification; Hypoparathyroidism; Hypocalcemia

\section{Case Report}

\section{Case 1}

A 33 year-old lady was admitted to the intensive care unit (ICU) with the history of a generalized tonic clonic seizure (GTCS) following a road traffic accident (RTA) 8 days ago. Regarding her past medical history, the patient had undergone a thyroidectomy two years ago for a benign thyroid condition. Her physical examination was unremarkable and vitals were within normal limits. On neurological assessment, she had spastic quadriparesis with stiffness of the shoulder girdle muscles. Chvostek and Trousseau signs were elicitable.

On admission, blood investigations showed hypocalcemia (total calcium of $4.6 \mathrm{mg} / \mathrm{dL}$ (normal level 8.4-10.5). White blood cell count, and hemoglobin level were $21,600 / \mathrm{mm}^{3}$, and $9.6 \mathrm{~g} / \mathrm{dL}$, respectively. The levels of urea nitrogen and creatinine were normal $(14 \mathrm{mg} / \mathrm{dL}$ and 0.9 $\mathrm{mg} / \mathrm{dL}$, respectively). The parathormone (PTH) level was $2.3 \mathrm{pg} / \mathrm{mL}$ (normal level 15-65 pg/mL) with an albumin of $3.3 \mathrm{~g} / \mathrm{dL}$. Vitamin D was found to be $24.4 \mathrm{ng} / \mathrm{dL}$. Computed tomography scan (CT scan) of the brain showed intracranial symmetrical calcifications of the basal nuclei with no compressive effect (Figure 1). The clinical examination and laboratory values and subsequent radiological investigations drove us to a diagnosis of Fahr's syndrome secondary to endocrinological dysfunction due to post-thyroidectomy HPT.

She was managed conservatively in the ICU with intravenous calcium gluconate, and ampicilin/sulbactam for respiratory infection and started on supportive oxygen therapy via $60 \%$ venturi. She was sedated to reduce the muscle stiffness and spasms.

On the third day, post admission, we initiated oral calcium and calcitriol. On the sixth day, we took her out of sedation and the patient showed active movements but with loss of muscle strength. The total calcium reached a level of $8.9 \mathrm{mg} / \mathrm{dL}$ by the thirteenth day of initiation of therapy. On the sixteenth day, she was discharged, stable, but with

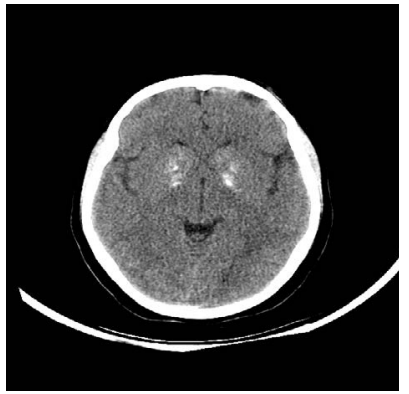

Figure 1: Computed tomography scan of the brain showed intracranial symmetrical calcifications of the basal nuclei.

mild disorientation. The scatter diagram showing the serum calcium levels during therapy is shown below (Figure 2). She has been on regular follow, ever since, and is asymptomatic since her discharge from the hospital.

\section{Case 2}

A 35 year-old patient presented with sudden onset of the worst headache of his life since the previous night. He was brought into the triage because of severe headache associated with multiple episodes of vomiting. On examination, his vitals were stable and neurological

*Corresponding author: Rajesh Parameshwaran Nair, Neurosurgery Registrar Department of Neurosurgery, Kasturba Medical College, Manipal University, Manipal India, Tel: +91-9611519911; E-mail: rajeshnair39@yahoo.com

Received October 01, 2015; Accepted November 13, 2015; Published November 16 , 2015

Citation: Nagaraj A, Nair RP, Ganapathy S, Lakshman IK (2015) Bilateral Basa Ganglia Calcification Secondary to FAHRs Syndrome: A Rare Entity. J Neurol Disord 4: 251. doi:10.4172/2329-6895.1000251

Copyright: @ 2015 Nagaraj A, et al. This is an open-access article distributed under the terms of the Creative Commons Attribution License, which permits unrestricted use, distribution, and reproduction in any medium, provided the original author and source are credited. 


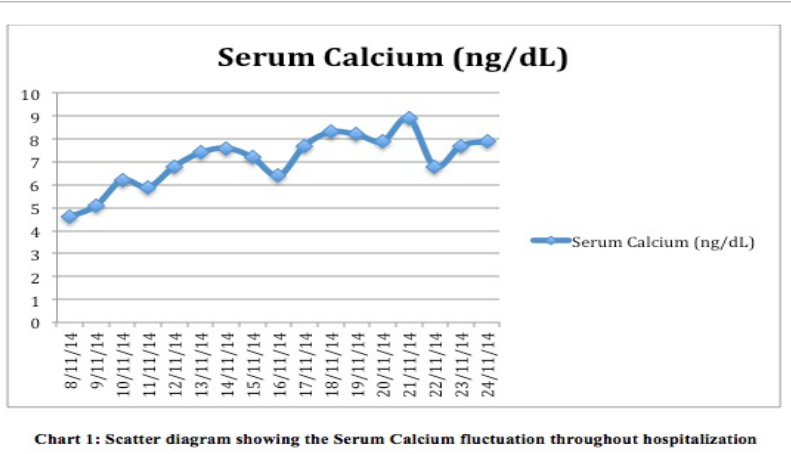

Figure 2: Scatter diagram showing the Serum calcium fluctuation throughout hospitalization.

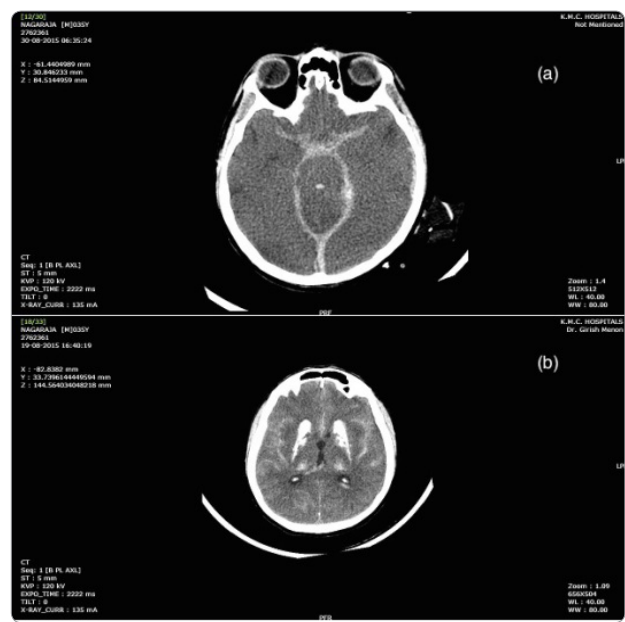

Figure 3: Plain CT of the brain (axial) (a) showing diffuse SAH within the opticochiasmatic cistern (b) showing dense calcification within the basal ganglia region.

examination was unremarkable except for mild disorientation. His pupils were equal and reactive. An immediate plain CT brain was ordered which showed diffuse subarachnoid haemorrhage, especially in the supra-chiasmatic cistern and was highly suggestive of an aneurysmal bleed. Another peculiarity noted in the scan was the presence of significant calcification in the basal ganglia region (Figure 3). He was evaluated for the same and his serum calcium and PTH levels were well below normal values. The patient however had a sudden deterioration in his glascow coma scale (GCS), the following day, and was discharged against medical advice and discharged from the hospital.

\section{Discussion}

Fahr syndrome or idiopathic calcification of the basal ganglia was first described by the German pathologist Karl Theodore Fahr in 1930, in a psychiatric patient with seizures, showing diffuse calcification in the cerebral vessels and basal ganglia [1].

Most common presentation are seizures, although rarely they present with extrapyramidal symptoms and neuropsychiatric signs. These symptoms have been explained by the symmetric, bilateral calcification within the nucleus pallidus, dentate nucleus, putamen and hemispheric white matter [2,3]. It is reported that in basal ganglia calcification, thalamocorticostriatal damage may trigger schizophrenialike syndrome with an incidence ranging from $0.3 \%$ to $1.2 \%$, reported on routine radiological examinations [4].
The primary pathogenic mechanisms of BGC are unknown, albeit it is believed to be due to poor calcium and phosphorus homeostasis, usually encountered in HPT. It is also associated with hypokalemia, and low calcium/phosphorus ratio [5]. Lipid deposition and demyelinization have also been implicated as a possible causative factor.

Various studies have showed a direct link between parathormone and BGC [5]. Microscopic examination of representative samples have shown intracerebral small vessel within the basal ganglia, cerebellum and white matter to have perivascular mineralization [6], that consists mainly of zinc, iron and magnesium hydroxyapatite enmeshed in a protein rich stroma without collagen or mucopolysaccharides [7].

The most common cause for basal ganglia calcification are disorders of calcium-phosphate metabolism, though many other clinical conditions have been associated with BGC, including inflammatory, infectious, tumor, endocrine, hypoxic, vascular, toxic, metabolic, and genetic disorders (Table 1) [8].

Among these conditions, the commonest cause for FAHRs syndrome, by far, seems to be endocrine diseases [3].

Radiological evidence of basal ganglia calcification mandates a thorough investigation for HPT, since it is one of the most frequently detected and easily reversible cause for psychiatric and seizure disorders in a patient with Fahr's syndrome.

The typical findings in untreated HPT include:

- $\quad$ Low circulation PTH levels

- Hypocalcemia

- Hyperphosphatemia

- Low levels of 1,25-dihydroxyvitamin D

- Relatively high urinary calcium excretion.

\begin{tabular}{|c|c|}
\hline Inflammatory & $\begin{array}{l}\text { Cytomegalovirus infection } \\
\text { Epstein Barr virus } \\
\text { Toxoplasmosis } \\
\text { Tuberculosis } \\
\text { HIV infection } \\
\text { Neurocysticercosis } \\
\text { Neurobrucellosis }\end{array}$ \\
\hline Toxic & $\begin{array}{l}\text { Carbon monoxide poisoning } \\
\text { Lead poisoning } \\
\text { Hypervitaminosis D } \\
\text { Radiotherapy }\end{array}$ \\
\hline $\begin{array}{l}\text { Metabolic and } \\
\text { degenerative }\end{array}$ & $\begin{array}{c}\text { Senility } \\
\text { Mitochondrial encephalopathies } \\
\text { Leukodystrophic diseases } \\
\text { Motor neuron disease } \\
\text { Myotonic muscular dystrophy } \\
\text { Carbonic anhydrase deficit } \\
\text { Biopterin deficit }\end{array}$ \\
\hline Endocrine & $\begin{array}{l}\text { Hypoparathyroidism } \\
\text { Pseudohypoparathyroidism } \\
\text { Hyperparathyroidism }\end{array}$ \\
\hline Tumoral & Astrocytomas \\
\hline Others & $\begin{array}{l}\text { Malabsorption } \\
\text { Downs syndrome } \\
\quad \text { Lupus } \\
\text { Tuberous sclerosis } \\
\text { Athrogriposis } \\
\text { Autosomal recessive }\end{array}$ \\
\hline Hypoxic and vascular & $\begin{array}{l}\text { Arteriovenous malformations } \\
\text { Calcified infarct } \\
\text { Ischemic encephalopathy }\end{array}$ \\
\hline
\end{tabular}

Table 1: Conditions associated with Basal Ganglia Calcification (BGC) on Neuroimaging. 
Citation: Nagaraj A, Nair RP, Ganapathy S, Lakshman IK (2015) Bilateral Basal Ganglia Calcification Secondary to FAHRs Syndrome: A Rare Entity. J Neurol Disord 4: 251. doi:10.4172/2329-6895.1000251

Page 3 of 3

Laboratory evaluation also should include serum creatinine, and magnesium levels.

In our case, the patient had undergone a total thyroidectomy with possible inadvertent removal or damage to the parathyroid glands, which had rendered her to a hypoparathyroid state [7,9]. Treatment is usually directed to this identifiable cause [10] and can prevent calcifications and neurophysiological disorders $[3,5]$.

Studies have shown that patients with seizures, parkinsonism and psychiatric symptoms respond well to correction of hypocalcemia to normal values and show poor response to anticonvulsants and other standardized treatments [3]. Dementia however has a poor response to this form of treatment and is generally irreversible. It is noteworthy that the prognosis is variable, cannot be predicted and is unrelated to the extent of calcifications [11]. Death is usually due to neurological deterioration [11].

Treatment of HPT, unlike other endocrine disorders, is not by replacement of the missing hormone, albeit subcutaneous synthetic preparation is available and used in refractory cases [1]. The standard line of management involves calcium and vitamin $\mathrm{D}$ supplementation with a goal to maintain a serum calcium and phosphorous level within the normal range, 24 -hour urine calcium under $7.5 \mathrm{mmol} /$ day $(300 \mathrm{mg} /$ day) and calcium-phosphate product under $55 \mathrm{mg} / \mathrm{dl}(4.4 \mathrm{mmol} / \mathrm{L})$

Though a rare clinical diagnosis, Fahr's syndrome should be considered in patients with neuropsychiatric disturbances and seizure disorder. In presence of BGC, HPT should be investigated, especially in patients who have undergone thyroidectomy, since in early stages this could be reversed with prompt and early diagnosis and treatment. This case report highlights the benefits of calcium supplementation and administration of calcitriol, even with the patient being in advanced stage of the disease.

\section{Acknowledgements/Competing Interests/Funding}

The authors have no competing interests and no funding from any agencies.

\section{References}

1. Fahr TK (1930) Idiopatische Verkalkung der Hirngefasse. Zentralblallg Path u path anat. 50: 129-133.

2. SwamiA, $\operatorname{KarG}(2011)$ Intracranial hemorrhagerevealingpseudohypoparathyroidism as a cause of fahr syndrome. Case Rep Neurol Med 2011: 407567.

3. Nicolau Ramis J, Espino Ibáñez A, Rivera Irigoín R, Artigas CF, Masmique Comas L (2012) Extrapyramidal symptoms due to calcinosis cerebri in a patient with unknown primary hypoparathyroidism. Endocrinol Nutr 59: 69-71.

4. Kazis AD (1985) Contribution of CT scan to the diagnosis of Fahr's syndrome. Acta Neurol Scand 71: 206-211.

5. Goswami R, Sharma R, Sreenivas V, Gupta N, Ganapathy A, et al. (2012) Prevalence and progression of basal ganglia calcification and its pathogenic mechanism in patients with idiopathic hypoparathyroidism. Clin Endocrinol (Oxf) 77: 200-206.

6. Unkrig S, Gullotta F, Madea B (2011) Morbus Fahr-considerations on a case of sudden death. Forensic Sci Int 204: e12-15.

7. König $P$ (1989) Psychopathological alterations in cases of symmetrical basa ganglia sclerosis. Biol Psychiatry 25: 459-468.

8. Arranz Pérez M, Ergueta Martín P, González Sarmiento E, Marañón Cabello A (1992) Fahr's disease and hypocalcemic syndromes. Presentation of a clinical case. An Med Interna 9: 495-497.

9. Castro MC, Singer BH (2012) Agricultural settlement and soil quality in the Brazilian Amazon. Popul Environ 34: 22-43.

10. Delgado-Rodrigues RN (1984) [Neurocysticercosis associated with hypoparathyroidism and Fahr's disease. Arq Neuropsiquiatr 42: 388-391.

11. Rastogi R, Singh AK, Rastogi UC, Mohan C, Rastogi V (2011) Fahr's syndrome: a rare clinico-radiologicentity. MJAFI 67(2):159-161. 